\title{
LANGUAGE PLANNING AND LANGUAGE IDEOLOGY: THE MAJORITY AND MINORITY DICHOTOMY IN NEPAL
}

\begin{abstract}
Language planning and language Ideology in Nepal have not been really responsive to the linguistic diversity. Nepal is a multiethnic, multi-religious, multicultural, multilingual, federal and democratic-republican country. It has two linguistic lines - linguistic majority and linguistic minority. This paper deals with the language planning and Ideology in Nepal since Panchayat regime to the present. This paper also advocates the strategy for government of governance. It allows for decentralization of power and recognizes and protects the linguistics rights of all Nepalese.
\end{abstract}

Raj Narayan Yadav*

Key words: Language Policy, Language Planning, Linguistic rights, Linguistic Pluralism.

\section{INTRODUCTION}

Nepal is one of the richest countries in the world as there are 126 ethnic groups plus one more category as unidentified caste and 123 languages plus one more category as unknown language (CBS, 2011).

\footnotetext{
This indicates that many of ethnic groups exist as minorities within larger inclusive political states and that emerging elites within these minority groups cannot but feel disadvantaged as they compete with members of the majority for position in the larger community. Nepal is made up of diverse ethnic groups, the majority of which have minority status. There are eight major languages in Nepal which are spoken as follows:

Nepali-44.6\%, Maithali-11.7\%, Bhojpuri-5.98\%, Tharu-5.77\%, Tamang-

$5.11 \%$, Newar-3.2\%, Magar-2.98\% and Awadhi- $2.47 \%$
}

Still Nepali is regarded as major language and 102 languages are regarded as minor. All languages spoken in Nepal have equal status and local importance, which are useful in their respective places. About $80 \%$ of the population speak Indo-European languages; about 19\% speak Tibeto-Burman languages and very small number of people in Nepal speak Austro-Asiatic and Dravidian languages (Yadav and Linsun, 2008).

Events in Nepal until the present in matters relating to language and other aspects of our socio-political inter-relations reflect ethnic consciousness. For instance the political party affiliation and voting patterns have seen mostly along ethnic lines. The Terai based political parties have political vision towards language. They want to speak in Hindi. Hindi is not used by any ethnic group in Nepal as their native language. Showing the relationship between language and politics in the concept of mother-tongue based multilingual education programme has been recently implemented in six districts. Language and politics are inter- 
related. Politics determines language policy of a country. The language policy causes success or failure of the national politics.

Late king Mahendra and his followers had adopted one nation-one language policy. Nepali was declared as the national language of Nepal and promoted only the use of Nepali in education, administration, media, court and publication. It was imposed to non-Nepali speakers over Nepal. Many above mentioned languages suffered. After democracy (1990) the constitution of Nepal entitled every language as national language but not the official language.

This language policy was declared by the followers of Mahendra Path. They were democratic leaders with undemocratic vision.

In fact, the Government of Nepal few years back had demonstrated some evil concepts towards the people of non-native Nepali speakers. The people of Terai proposed that the official work in Janakpur, Rajbiraj, Siraha, etc should be done in Maithali along with Nepali. Similarly, the people of Kathmandu valley proposed that the official work should be done in Newari along with Nepali. The proposal had been rejected by Supreme Court in the influence of Nepali speakers. It was done based on the theory of Bahunism. It was very unfortunate for those undemocratic minded people to think like this that the national integrity break using other languages for official purposes in certain regions.

The Constituent Assembly declared Nepal a Federal States late even in different government services followed by the theory of inclusiveness, which will give the opportunity for disadvantaged people. However when it comes to the utilization of linguistic resources of Nepal, the minority languages are not recognized as such. This will be evident when we take a look at language planning attempts in Nepal.

\section{LANGUAGE PLANNING IN NEPAL}

Language Planning is a deliberate, systematic and theory-based making attempt in response to language problems of a community by studying its various languages or dialects and developing an official language policy concerning their selection and use.

Weinstein (1980) as quoted by Wardhaugh (2006: 356) defines language planning as 'a government authorized, long-term, sustained, and conscious effort to alter a language's function in a society for the purpose of solving communication problems'. It is often associated with government planning, but is also used by a variety of non-governmental organizations, such as grass-roots organizations and even individuals. Thus, the first focus of language planning can be regarded as status planning. Status planning refers to the modification in the role or status of a language or a variety in a certain society. It is a political activity and often the people in the power try to assign their own language a higher status. In Nepal $80 \%$ political leaders in different political parties are Pahari and Bahun. They are in power from Panchayat period to Republican period. They are mostly Nepali speakers so they have given Nepali a higher status.

According to Spolsky (1998: 66) "In a situation where there are seen to be two or more languages available, any attempt to set up norms or rules for when to use each is what is called Status Planning." 
William Stewart outlines ten functional domains in Language Planning. They are; official, provincial, wider communication, international, capital group, education, religious, literatures and schools.

There has not been a comprehensive language policy in Nepal as deliberate and planned exercise. Of course language planning as an organized and systematic pursuit of solutions to language problems has remained largely peripheral to the mainstream of national planning. National Language Policy Recommendation Commission (1993) suggested designing mother tongue curriculum and textbook with the aims of introducing the mother tongue as the medium of monolingual and transitional bilingual primary education and literacy programme.

Article 7 of 1971 Education Act of Nepal stated that the medium of instruction in school shall be the Nepali language. Most languages matters in Nepal have not been planned. The constitution of Nepal 1990 had recognized Nepali as the 'language of the nation' and all the mother languages spoken in Nepal as its 'national language' in Article 6. In addition, the constitution had also adopted the policy to promote and preserve Nepal's national languages.

According to Yadav (2003: 158) "it had been for the first time that some constitutional provision has been made for languages other than Nepali in consonance with the existing linguistic plurality in Nepal."

According to constitution of Nepal 1990, 'The business of National Assembly be shall conducted in Nepal and the business of the House of Representative shall be conducted only in Nepali. Except Nepali, not any other languages were allowed in Legislative, executive and Judiciary.' This is known as the theory of dominant. All people except Nepali speakers were against it. Emotional volcanos regarding languages were in their mind.

The interim constitution of Nepal 2007 has removed the tradition of the language of nation and national languages distinction and asserts that all languages spoken in Nepal are national languages. The Nepali language has been regarded as an official language of the nation.

National Languages Policy Recommendation Commission submitted its report to Ministry of Education, Culture and Social Welfare on 31 Chaitra, 2050 BS and among the 58 recommendations made under various headings, the following have been identified as the major ones:

(1) to conduct a linguistic survey of Nepal and to promote the languages of Nepal by codification and linguistic description and to develop the uses of these languages in education and vehicles of mass communication,

(2) to identify the endangered languages and take steps for their preservation,

(3) to classify languages into three groups; i.e. those with established written traditions such as Nepali, Newari, Maithili, Limbu, Bhojpuri, Awadhi, Tibetan; the second with an emerging tradition of writing, e.g. Tharu, Tamang, Magar and Gurung and the third without any script or written literature for the purpose of imparting Primary Education in the mother tongue,

(4) to promote mono-lingual/bilingual education in mother tongue or Nepali on the basis of ethnic composition of students in particular areas, and 
(5) all students to have the right to receive education either in the mothertongue, mother-tongue with Nepali or Nepali along and upto lower secondary level to have the opinion to study their mother tongue as a subject in place of Sanskrit.

But there is no commitment for the recommendations to be implemented. It appears that the present government is concerned with constitutional and political issues. Linguistic issues are not in the priorities of the government.

Now we see that radios, televisions and newspapers include something from minority languages. News is read in Nepali, English, Maithali, Bhojpuri, Tamang, Newari, Limbu, etc. in radios and televisions. The conflict between the major and minority languages has persisted till now. It is true that minority languages speakers are only using languages as a symbol. Language Planning in Nepal interms of majority/minority dichotomy will be solved if the country creates federal states according to language community. Nepal has given importance to Nepali language because political figures are in the favour of Nepali. Some scholars have recommended two from Nepali, English, Maithali, Bhojpuri, Awadhi, Limbu, Rai, Tamang, Newari, for the purpose of national integration. Multilingual approach has been supported for the elevation of first, second and third groups of languages. Some linguists of Nepal recognized the status of English for international culture and recommended in Education System of Nepal because all private schools are in English medium. Language Policy and Planning efforts can be hinged on a well-articulated ideology and all other aspects of Nepalese life must be in conformity with this ideology that may inform language planning is such a multilingual setting of Nepal.

\section{IDEOLOGY IN LANGUAGE PLANNING}

Ideology means the belief or principle that influences something. Cobarru bias (1983) has described four typical ideologies that may motivate actual decision-making in language planning in aparticular society: linguistic assimilation, linguistic pluralism, vernacularization and inter-nationalism. Linguistic assimilation is the belief that everyone regardless of origin, should learn dominant language of the nation. Linguistic Pluralism is the recognition of more than one language. Within a country a larger society may require more than one language in its administration, judiciary, education and executive.

Singapore has four official languages: Chinese, Tamil, Malay and English. Singapore is smaller than Nepal in size, population and languages still this concept is not adopted here. Vernacularization refers to restoration or elaboration of an indigenous language and its adoptation as official language. e.g. Hebrew in Israel, Jok Pisin in Papua New Guinea. Internationalism is the ideology supporting a non-indigenous language of wider communicative for education, trade and official language.

In multilingual country like Nepal language planning must realistically confront the problem of ethnicity and come up with a policy that will cater for the yearnings and aspirations of all segments of Nepal. The responsibility of government of Nepal to promote the status of all languages spoken in country and to unite its people through the use of minority and majority. If minority languages are not 
respected and promoted, there may occur a conflict among people. Every Nepali will have a sense of belonging and equal opportunity to participate in development of Nepal. Every citizen is equal in every country. So, majority and minority languages are equal. According to Rousseau (1993: 17) "two thirds of Quebecers Speak no English in Canada, English Speaking majority and French Speaking minority." They were demanding their linguistic rights not only in their province but also in Canada. Government has fulfilled their linguistic rights. People hope that government of Nepal will provide guarantee to status of minority languages. They will get linguistic rights and will use their languages in all fields. Then the age-long Nepali-speaking dominance is now gradually receding.

\section{CONCLUSION}

Nepal will be in Federal Structure. Each state must be allowed to have their own linguistic policies and planning strategies without prejudice to whatever recommendations that obtains at the central government. It helps to develop different minority languages including national language. Education upto secondary level should be in local languages and adult education and women education should be made possible in every language in each state. Minority languages speakers themselves have a role to play in the development of their languages. They should write stories, dramas, poems, grammar, proverbs and cultural issues in their mother tongue. Educationalists, linguists, writers and scholars must provide educational materials in minority languages, then minority languages enhance their development.

We see the condition of minority and majority languages and their interrelation. There is a social conflict among majority and minority languages speakers. Language is a precious resource of people. They are intellectual wealth for them. They are their identity and verbal art. So, experts, linguists, political leaders and others have to bring linguistic equality and develop all Nepalese languages for integration and realization of minority and majority languages. They should follow the planning system of Singapore and bring harmony with linguistic vision for the development of Nepal

\section{WORKS CITED}

Cobarrubia, J. (1983). Progress in language planning. International Perspectives. Monton Publishers, The Hague.

Constitution of Nepal 1990, HMG.

Education Act of Nepal 1971, MOE, HMG.

Interim Constitution of Nepal 2007, GON.

National Languages Policy Commission 2050 BS, HMG.

Oluwole, S. (2003). Language planning in multi-ethnic state. Norvic Journal of African Studies.

Rousseau, M.O. (1993). The politics of language and trade in Quebec. Toward an Autonomous Francophone State. University of Nebraska at Omaha, Canada.

Spoksky, B. (1998). Sociolinguistics. OUP, Oxford. 
Steward, A. (1969). "Sociolinguistic typology of multilingualism." Readings in the sociology of language. Ed. Joshuh Fisherman, Monton Publishers, The Hauge.

Wardhaugh, R. (2006). An introduction to sociolinguistics. Blackwell Publishing Ltd., Oxford.

Yadav and Linsun, (2008). Language policy in Nepal. A study of languages of Nepal. 